\title{
Study on the Teaching Mode of Practice Orientation-based Workshop -taking the workshop of digital art creative research and development center in animation school of Shenzhen Polytechnic for instance
}

\author{
Li Chen \\ Shenzhen Polytechnic, Shenzhen, 518055, China
}

Keywords: Workshop. Teaching mode. Digital art creative

\begin{abstract}
Based on the clarifying the concept of workshop, the concept of practice orientation and their relationship, and took the workshop of Digital Art Creative Research and Development Center in Animation School of Shenzhen Polytechnic for instance, this paper aims to establish a teaching practice mode of “one 'carrier', two 'support' and three 'transformation'” for the Digital Art Creative Workshop, with a combination of art and technology: taking workshop as the carrier, taking the innovative research team and innovative project course as the two supports and taking works joining an exhibition \& competition and achievement transformation as important target and evaluation mechanism.
\end{abstract}

\section{Introduction}

As a kind of new participative teaching mode, workshop is featured with initiative, participation, and openness and possesses advantages and application values in comparison with the traditional teaching mode in colleges, hereby, research and practice about workshop have obtained increasing attention from the colleges, especially from the higher vocational colleges, and took it as the research focus of future educational reform. However, how to scientifically apply workshop to teaching practice in colleges and how to establish systematical working process, teaching mode, teaching staff and teaching evaluation, etc. Of workshop are urgently need studying and solving. Based on the clarifying the concept of workshop, the concept of practice orientation and their relationship, and took the workshop of Digital Art Creative Research and Development Center in Animation School of Shenzhen Polytechnic for instance, this paper aims to establish a teaching practice mode of "one 'carrier', two 'support' and three 'transformation'” for the Digital Art Creative Workshop, with a combination of art and technology

\section{The concept of workshop and current situation}

"Workshop" was firstly produced in the educational and psychology fields. In 1960s, lawenceharplin applied the concept of workshop to city planning, making it a way for people with different positions and groups to think, discuss and communicate with each other, a way to encourage participating in, innovate and find the solution. Applying workshop to teach art was produced in Bauhaus school, which was established on April 1, 1919. At that time, workshop was also called as "Collective workshop". In the more than 150 years development process after the industrial Revolution of Europe, the modern western design education gradually formed the "project design"-centered teaching mode ${ }^{[1]}$.

At present, higher educational world gradually applied "workshop" to education and teaching field, formed one of the international popular teaching modes. For instance, the "Creative College" established in Guangzhou Academy of Fine Arts, "workshop system" implemented in Central Academy of Fine Arts and Zhejiang University, "Outcome-based Education" in the Hong Kong Polytechnic University, "animation teaching workshop” in Communication University of China, "international urban design workshop" in Zhejiang Gongshang University, "care managers training workshop” in Medical College of Shantou University, Design and Application of "practical teaching 
workshop" of Ge Hua, an associate professor of Shenzhen Polytechnic, and so on. In short, in China, research and practice about workshop have obtained increasing attention from the colleges, especially from the higher vocational colleges, and took it as the research focus of future educational reform.

\section{Concept of practical value orientation-based workshop and characteristics study}

\section{Concept of practical value orientation}

Value orientation is an important part of value philosophy, which refers to the basic value standpoint, value attitude and the demonstrated basic value orientation of certain subjects as they face with or deal with all kinds of contradictions, conflicts and relations on the basis of their values. The so called practice orientation means that in the subject activities, placing practice in the core value position to fully exert the practice's fundamental function in subject activities. That's to say, in the process of training cultural and creative professionals, practice orientation is an essential requirement, which is particularly important and distinctive in the process of training professionals in vocational colleges, as personnel training is a practical activity in training talents. In terms of personnel training, the concrete concept of practice orientation can be summarized into three aspects: for practice, practice-based, in practice. "for practice" is the goal of practice orientation. "practice-based" is the foundation of practice orientation and "in practice" is the field of practice orientation ${ }^{[2]}$. Workshop itself is a kind of project teaching mode based on practice, and practice orientation is the internal requirement for workshop.

\section{Concept of practical value orientation workshop and characteristics study}

We can see from the above analysis on workshop and practice orientation that workshop is a kind of new participative teaching mode. Its features of initiative, participation and openness determined its practical value orientation. Workshop is a kind of new personnel training teaching mode of "practice-based, in practice and for practice" in essence, which becomes a strong platform and feasibility mode for practical teaching in college. The workshop concept based on practical value orientation includes the following basic characteristics:

\section{Practicalness}

Compared with traditional teaching mode, the workshop concept based on practical value orientation has its own basic characteristics, firstly, is the practicalness. Workshop practical teaching is synchronized with theoretical teaching in the whole process, i.e. Learning theories on the basis of the practical requirements, instead of taking theory as the core. It is assisting practice according to the requirements of learning theory ${ }^{[3]}$. The ultimate goal of workshop teaching mode is for students to achieve better practice in the future, i.e. The basic goal of "for practice". In vocational college, training students' practical ability is a basic task, which requires students to exercise themselves in practice and help students to get experience in practice, form practical ability and obtain knowledge and skills.

\section{Authenticity}

The practicalness of workshop teaching mode determined the authenticity of its learning environment, which is particularly important in developing students' operational ability and the ability to apply technology in the real environment of vocational college. Therefore, workshop mostly adopts real projects to implement practice teaching, to provide students with authentic learning environment, in which students can participate in the practice of real projects.

\section{Initiative}

Compared with the traditional passive learning, workshop makes it possible that students take initiative in practical learning. Traditional teaching mode is based on instruction, while workshop is led by practical activities and taking experience as the core. Workshop teaching mode has widely replaced the traditional teaching and training mode in Europe. For instance, practical learning is very important in learning computer, personal operation is all-important in learning driving a car, and so on. For the students in vocational colleges, this practical teaching mode is more important and complies with students' actual situation. 


\section{Cooperation}

In the workshop teaching mode, cooperation is always throughout the teaching process, and in other words, the teaching process is a cooperated specific teaching mode. The students' practice is completed in cooperation, and the advantages are the learning effectiveness is better and more durable, and team spirit can be built through cooperation.

\section{Constructiveness}

The knowledge acquisition is generated in practice and which is constructed and developed in interaction. In the workshop teaching mode, teachers are no longer instructors of knowledge, they are more like leaders in guiding students in independent knowledge learning and skills acquiring. The main responsibilities of the teachers are helping students in understanding constantly changing environment and themselves, to maximize their potentials, so that students change from passive recipients of knowledge into the initiative builder of their life meaning.

\section{The workshop of Digital Art Creative Research and Development Center in Animation School of Shenzhen Polytechnic}

Based on the theory and practice of the workshop teaching mode, The workshop of Digital Art Creative Research and Development Center in Animation School of Shenzhen Polytechnic aims to establish a teaching practice mode of “one 'carrier', two 'support' and three 'transformation'”, with a combination of art and technology, i.e. Taking workshop as the carrier, taking the innovative research team and innovative project course as the two supports and taking works joining an exhibition \& competition and achievement transformation as important target and evaluation mechanism (shown as Fig.1).

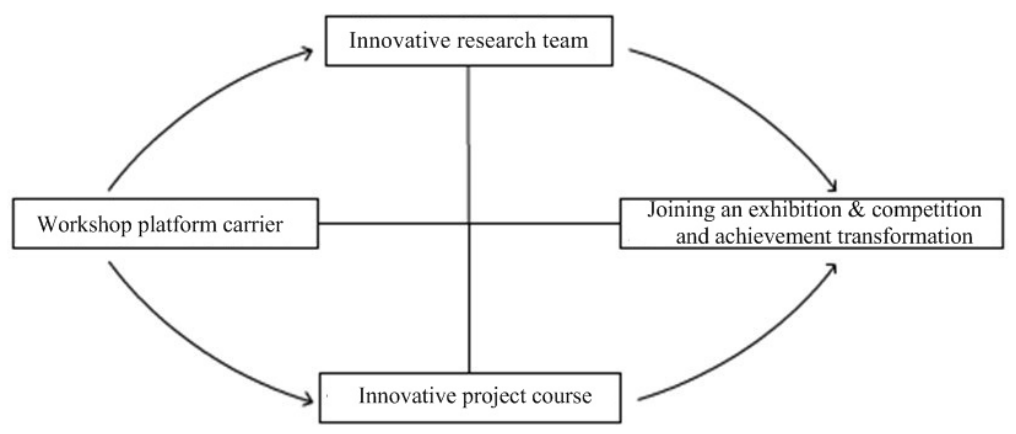

Fig. 1 Flow Figure of Practice Orientation Workshop Teaching Mode

\section{Taking workshop as carrier}

The traditional teaching space is generally classroom, which is the teaching environment of traditional three centers. Workshop teaching mode takes workshop as platform and teaching innovation environment. Since 2012, the Animation School of Shenzhen Polytechnic has successively set up a number of studios, workshops and research centers, among which the workshop of Digital Art Creative Research and Development Center has been set, which provided the students training in this college with a new approach. The workshop became a true platform and carrier for the training personnel and for communication between colleges and enterprises. For instance, through this Digital Art Creative Research and Development Center, the sculpture "Dragon Has Nine Sons (refers to good and bad intermingled)" completed by students under the guidance of professor Zhou Linyi and other teachers participated in the 2012 Eighth China ( Shenzhen ) International Cultural Industry Fair and won praise from the field.

Taking the innovative research team and innovative project course as the two supports

\section{Innovative research team}

Teacher team building is critical for better implementation of workshop teaching mode. Since 2012, Shenzhen Polytechnic has been launching the reporting of innovative research team, and the workshop actively preparing innovative research team of "interactive media and entertainment games”. The team's working idea: Centered on Shenzhen's development planning of "the 12th 
Five-Year Plan" and Cultural Development Program of Shenzhen, closely connect with the personnel training strategy of "three cultivating" to establish interactive media based on applied technology research and platform for innovative research and applied service of entertainment games, promote the important applications of digital interactive technology in the development of the cultural industry, making interactive media and entertainment games innovations become an important factor and an important support in the cultural industry development of Shenzhen, strive to establish digital technology public service platform relying on the Animation College of Shenzhen Polytechnic and interactive media and entertainment games innovative research and application development center radiating the Shenzhen areas.

\section{Innovative project course}

Innovative course set is the key to better promote the workshop teaching model. Compared with the traditional course form, workshop teaching mode focuses on "project" courses, which are the major course forms of workshop teaching mode. Since 2010, Shenzhen Polytechnic has been implementing project course reform, and the teachers from Digital Art Creative Research and Development Center in Animation School of Shenzhen Polytechnic actively reported, including teaching course project of Study on Training Mode of Versatile Talents, innovation project of Overall Research and Development of Flash Anime Textbook of Chinese Teaching in Primary School, and so on.

Taking exhibition \& competition and achievement transformation as important target and evaluation mechanism

In order to change the traditional teaching evaluation mode that centered as examination evaluation and knowledge test, workshop teaching mode emphasizes on the students' practical ability, and the reformed and innovated the appraisal form and method. Therefore, this Digital Art Creative Research and Development Center proposed the evaluation mechanism of taking exhibition \& competition and achievement transformation as important targets. In this workshop, the sculpture "Dragon Has Nine Sons (refers to good and bad intermingled)" completed by students under the guidance of professor Zhou Linyi and other teachers participated in the 2012 Eighth China (Shenzhen) International Cultural Industry Fair. This work tested the students' operational ability and practical ability.

\section{Acknowledgments}

This paper is one of the 2012 college level key teaching and research project Research and Practice of "Workshop" teaching mode — Taking the Workshop of Digital Art Creative Research and Development Center in Animation School for Instance of Shenzhen Polytechnic education and teaching research subjects (project number: 2212J3090015, host: Chen Li).

\section{References}

[1] Qiu Zhitao, Zhang Jingwei. Study on "Workshop” Elite Teaching Mode in Artistic Designing Course. Packaging World, 2012(9):74-78.

[2] Chen Li. Practice of Personnel Training Mode for “Industry-University-Research Cooperation” of Practice Orientation. Vocational and Technical Education, 2013(26):63-65.

[3] Liu Yu. Study on Workshop-Based Practice Teaching System of Higher Education. Academic Journal of Dongbei University of Finance and Economics, 2009(1):93-96.

[4] Huang Yue. The Role of University Teachers in the Workshop Teaching Mode: Taking Translation Course Teaching for Instance. Education \& Science of University, 2011(6):56-60.

[5] Zhao Jing Lei. Opinions on Workshop Teaching Mode . Proceedings of The First Colleges' Art and Design Forum in China (II),2010(12):942-948.

[6] Li Lei. Study on Teaching Practice of Workshop in Industrial Design. Art Education Research, 2011(11):128-129.

[7] Ge Hua. Design and Application of "Practical Teaching Workshop”. Educational Theory And Practice,2011(6):45-47. 